\title{
BIOMETRIC BASED ATTENDANCE REGISTRATION AND CONSOLIDATION SYSTEM USING RASPBERRY PI3 AND AMAZON WEB SERVER
}

\author{
Dr. Dhiraj Sunehra \\ Department of Electronics \& Communication Engineering \\ Faculty of Engineering \& Technology \\ Jawaharlal Nehru Technological University Hyderabad, India
}

\begin{abstract}
Conventionally, in schools and colleges, attendance is taken by the teacher by calling students names or roll numbers, mark his or hers presence or absence in the attendance register. Later attendance is fed into a computer and the attendance percentage is calculated using software in offline mode. This method is time consuming and also requires more man power. In this project, a portable Biometric based Attendance Registration and Consolidation System (BARCS) using Raspberry Pi3 and Amazon Web Server is developed. This handheld biometric attendance registration device can be carried by the teacher to the classroom to register the student's attendance of a particular session through circulation among students. At the end of a session, attendance data gets stored in a database in the Raspberry Pi computer. Then, Pi computes the subject wise attendance percentage and sends it to the Amazon web server for uploading on the developed webpage. The user can view the subject wise attendance by accessing the webpage. Also an SMS is sent to the students mobile when their attendance gets registered. The developed system is intended for programmes wherein students have to meet the minimum attendance requirements in each subject of the programme in a particular semester/year.
\end{abstract}

Keywords: Handheld Biometric Attendance Registration Device, Raspberry Pi3, Python language, PHP, Amazon Web Server

Cite this Article: Dr. Dhiraj Sunehra, Biometric Based Attendance Registration and Consolidation System Using Raspberry PI3 and Amazon Web Server, International Journal of Advanced Research in Engineering and Technology, 10 (2), 2019, pp 34-43. http://iaeme.com/Home/issue/IJARET?Volume=10\&Issue $=2$

\section{INTRODUCTION}

Around the world, in several educational institutions, presence or absence of the students for the classes of various subject teachers is taken into consideration to decide whether a student is eligible to appear for the semester end or annual examinations or not. It also shows the students 
interest in the subjects, and play a vital role in the smooth functioning of the academic system and maintaining the reputation of the institution.

In many institutions, biometric attendance system is being used nowadays. Many a times, biometric attendance is taken once in a day or incoming or outgoing fingerprints are taken. This method indicates the presence of the student in the campus, but does not gather session wise attendance which is needed for calculating student's attendance percentage, to decide whether or not, he (she) fulfils the academic requirements to appear for the examinations.

\section{LITERATURE REVIEW}

Srinidhi and Romil Roy have used RFID and biometrics to develop a web based attendance monitoring system. The system can detect location of the student or faculty within the campus. Also an automated SMS is sent to the parent's mobile, when their ward reaches the college. An email is sent to both parent and student, if the student falls shortage of attendance [1]. Amena Khatun et al implemented a biometric-based attendance system that can automatically capture students' attendance by recognizing their iris [2]. Poornima et al presented an automated attendance system based on face recognition [3]. Sunil Jadhav et al have used a smart phone application, where in the mobile device acts as a scanner to scan the QR code present on the student's ID card and register the student's attendance [4]. Sunehra and Goud have implemented an arduino based attendance recording device using keypad and LCD. The recorded attendance is sent from this device via ZigBee to a Raspberry Pi web server to display the consolidated attendance onto the webpage [5].

\section{SYSTEM DESCRIPTION}

\subsection{Block Diagram of the BARCS}

Figure 1 shows the block diagram of the Biometric based Attendance Registration and Consolidation System (BARCS). In this system, fingerprint sensor acts as an input device connected to the Raspberry Pi through RS232 to USB converter. LCD and GSM modules are used as output devices.

Raspberry Pi is the centralized component which is interfaced with all the devices. Initially the students and faculty need to register their fingerprints. To start taking attendance, the subject faculty will first login by placing his fingerprint on the sensor module to start the session. Then the handheld biometric attendance registration device (BARD) is circulated in the class so that all the students present in the class can register their attendance by placing their fingerprint on the module. When any student or faculty places his finger, the biometric device will scan his fingerprint and compare with the database of fingerprints present within the fingerprint module. If the fingerprint matches, the output of fingerprint module is logic 1 , otherwise it is logic 0 . The attendance of students (for whom output is logic 1) is stored in the Pi. At the end of the class (session), the subject teacher will again place his fingerprint on the sensor module to close the session.

Then Raspberry Pi will update the attendance of all the students, and the consolidated attendance and corresponding attendance percentages will be sent to the Amazon Web server for uploading the attendance information of that subject on to the webpage. Similar process will continue for each session. Whenever the student or faculty registers the attendance, a message "Finger found" is displayed on the LCD and a SMS is sent to their mobile number. 


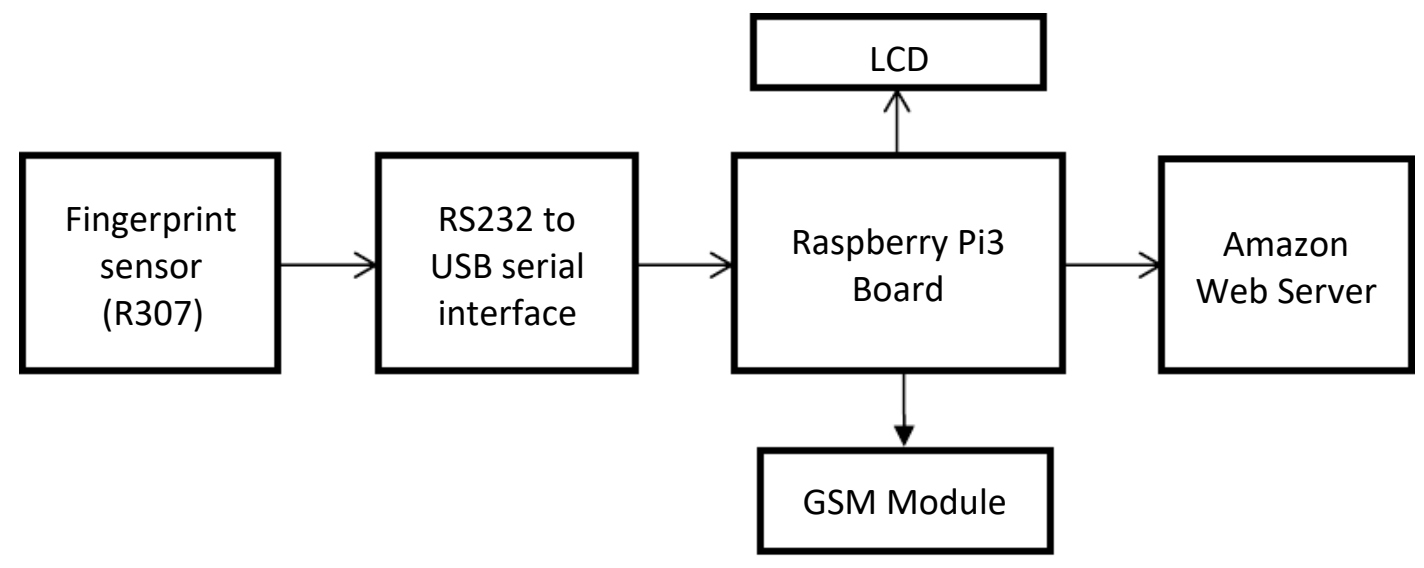

Figure 1 Block Diagram of Biometric Based Attendance Registration and Consolidation System

\subsection{Raspberry Pi3}

Raspberry Pi3 is a small sized, single-board computer. It has a Broadcom BCM2837 System on Chip (SoC) module. It has a 64-bit quad-core ARMv8-Cortex-A53 processor. By default, it is operating at $1.2 \mathrm{GHz}$. The Raspberry Pi3 Model B is shown in Figure 2.

The Raspberry Pi3 requires a 5V, 2.5A DC supply. For storage purpose, Raspberry Pi requires an external micro SD card, as it does not have any internal storage or hard disk on board. Raspberry Pi3 consists of 40 pins, out of which 26 are general purpose input and output (GPIO) pins. It has one Ethernet port which is used to provide internet to the Raspberry Pi. It has four USB ports and Bluetooth connection. Raspberry Pi3 has 1GB RAM memory and 512 $\mathrm{MB}$ is shared with graphical processing unit (GPU) [6]. It has BCM43143 wireless LAN to provide Wi-Fi. It consists of a 15 pin MIPI camera serial interface.

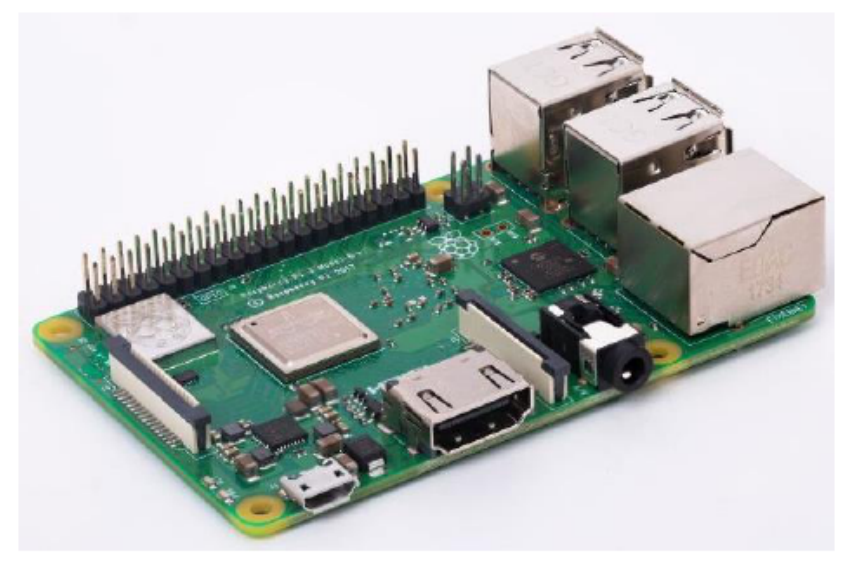

Figure 2 Raspberry Pi3 Board

\subsection{Fingerprint module}

Fingerprint module has an optical fingerprint sensor and a high speed DSP processor (Figure 3). It is a digital input device, which reads the digital data from the user (in the form of fingerprint) and generates output as $2 \mathrm{D}$ or $3 \mathrm{D}$ image. When a fingerprint matches with already registered fingerprints, the output of the module is logic 1 , otherwise it is logic 0 . The storage capacity of R307 Fingerprint module is 1000 . It consists of six GPIO pins. Fingerprint module requires a RS-232 cable for serial communication at a baud rate ranging from $9600 \mathrm{bps}$ to $115200 \mathrm{bps}$. 
Biometric Based Attendance Registration and Consolidation System Using Raspberry PI3 and Amazon Web Server

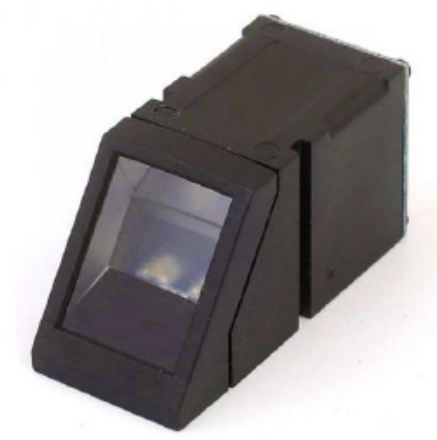

Figure 3 Fingerprint module

\subsection{GSM SIM900A Modem}

Figure 4 shows the GSM SIM 900A modem. To connect GSM to the microcontroller or PC, it requires a RS-232 interface connector. It is a Dual-band GSM operated with frequencies $900 / 1800 \mathrm{MHz}$ [7]. Internet access (2G) is provide through the inbuilt TCP/IP stack and it uses Time division multiple access (TDMA) technique. It is mostly used for sending SMS, voice and data transfer applications. It can adjust the baud rate from 9600 to 115200 by using simple AT commands.

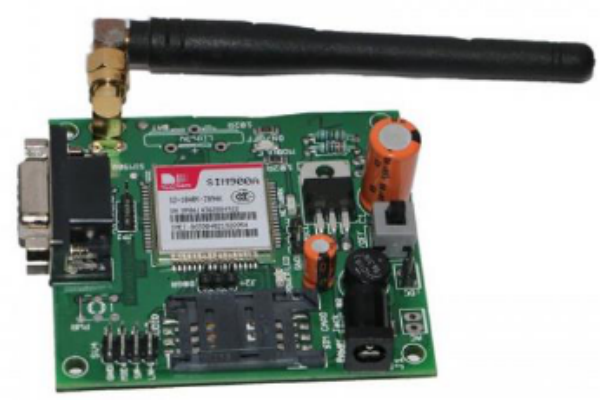

Figure 4 GSM SIM 900A modem

\subsection{LCD}

LCD is an electronic display. A $16 \times 2$ LCD displays 16 characters in single line, two such lines are present. It operates at a voltage of $5 \mathrm{~V}$ DC. It consists of two registers, viz. command register and data register. To store the instructions of the command for the LCD, command register is used. For the LCD, predefined task can be done by AT commands. Predefined functions include clear screen, placing of cursor position, to control the display and soon. To store data on the LCD, data register is used.

\subsection{Software Tools}

We use various software tools such as ExtraPuTTY, Python, HTML and PHP in the implementation of BARCS. To login to the Raspberry Pi and to communicate with the server Extra PuTTY software is used [8]. Raspberry Pi uses a high level programming language such as Python. C Python is the most widely used interpreted language because of its portability, and it has a extensive pre-coded libraries [9]. The webpage designing is done using HTML and PHP to show the attendance subject wise [10]. 


\section{SCHEMATIC DIAGRAM AND FLOWCHART}

\subsection{Schematic Diagram of the system}

Figure 5 shows the schematic diagram of Biometric Based Attendance Registration and Consolidation System.

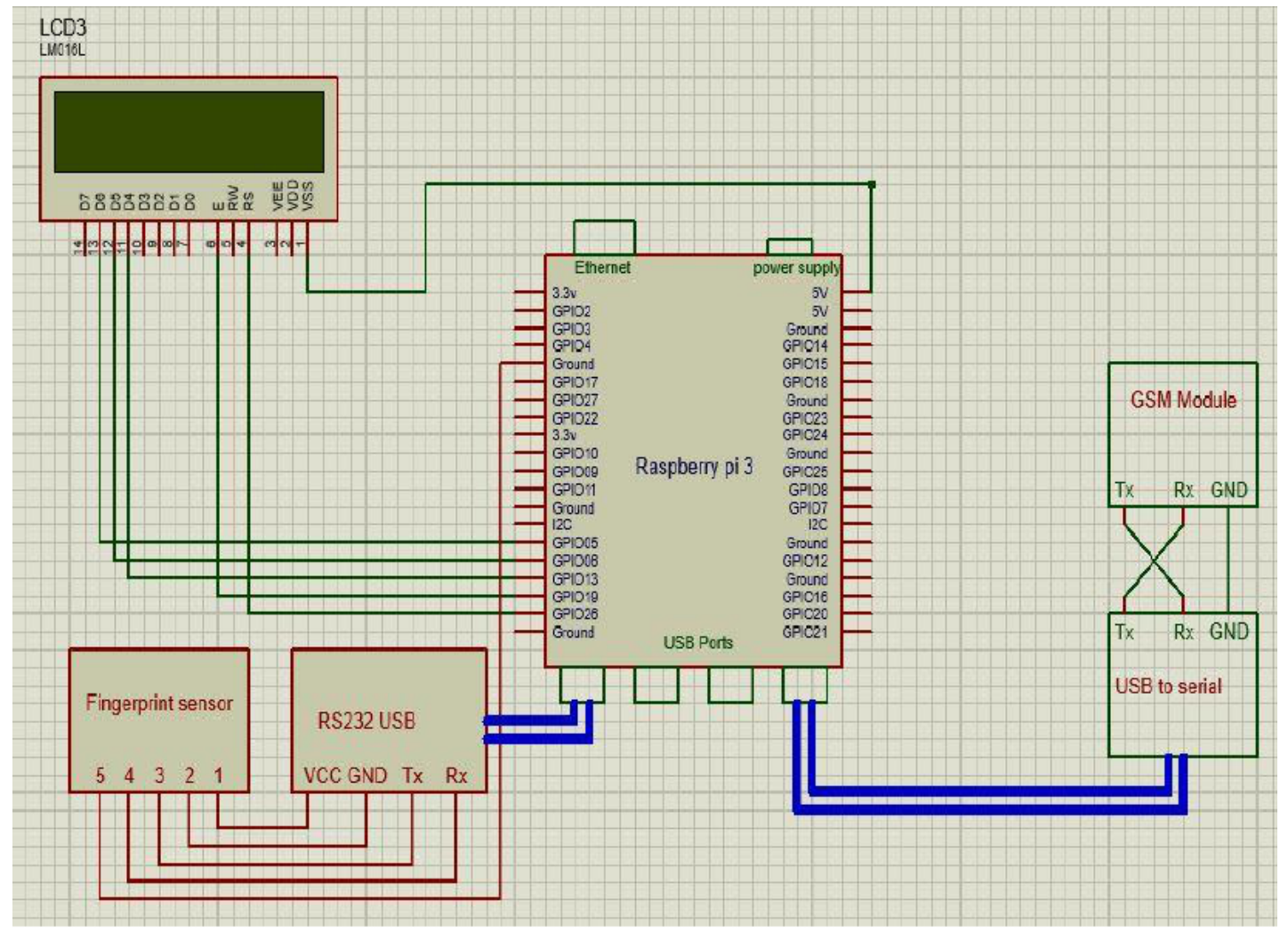

Figure 5 Schematic Diagram of BARCS

\subsection{Flowchart}

The flowcharts of the sequence of events that occur in the Biometric Attendance Recording and Consolidation system and User side are shown in Figure 6 and Figure 7 respectively. When the system is initialized, all the components like fingerprint sensor, GSM module, LCD are initialized. The faculty has to give his/her fingerprint to the sensor, if it is matched, then the Name of the faculty, course code is displayed on the LCD. Then the system allows students to register their fingerprints. If student fingerprint is matched, name of the student and ID number is displayed on the LCD. GSM module then sends a SMS to the student as "your attendance is registered". After certain period of time all the students give their attendance by registering their fingerprints using the handheld biometric attendance registration device (BARD).

When the session time is completed, the faculty again has to give his/her attendance to close the session. The Raspberry Pi computes the attendance of each student and the entire data will be updated to the SQL database, and it will be uploaded to the Amazon Web server. The webpage displays the attendance percentage of each student for each subject. 
Biometric Based Attendance Registration and Consolidation System Using Raspberry PI3 and Amazon Web Server
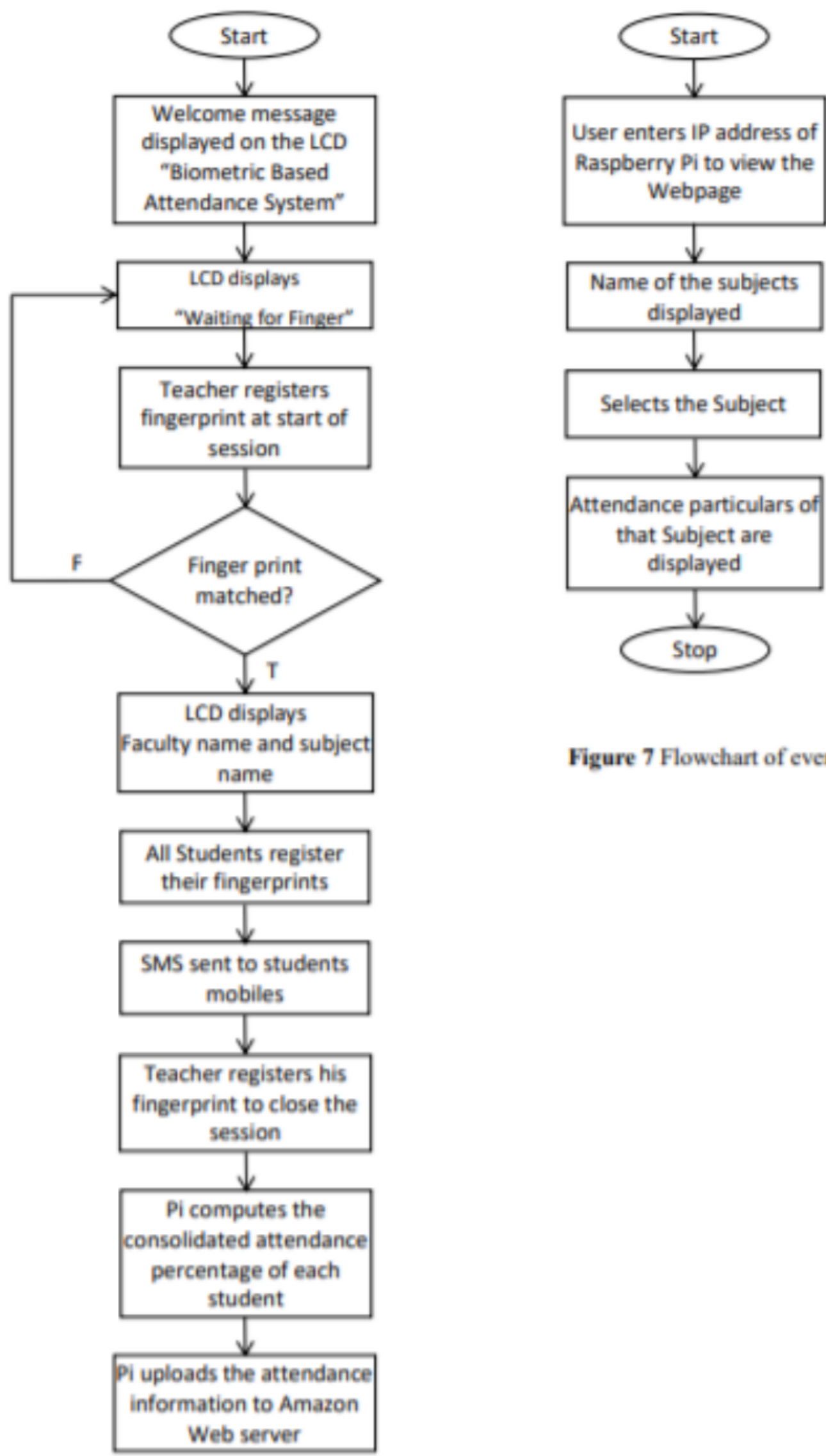

Figure 7 Flowchart of events at User side

Figure 6 Flowchart of BARCS 
The above procedure is used for all the sessions of a particular course and other courses in the semester/year. The student or parent can check the consolidate attendance percentage at any point of time on the webpage by entering the IP address of Raspberry Pi. Hence this system gives the attendance subject-wise as desired.

\section{EXPERIMENTAL SETUP AND RESULTS}

Figure 8 shows the experimental setup of Biometric Based Attendance Registration and Consolidation system using Raspberry Pi. The various modules such as fingerprint sensor, LCD, GSM module are interfaced with the Raspberry Pi.

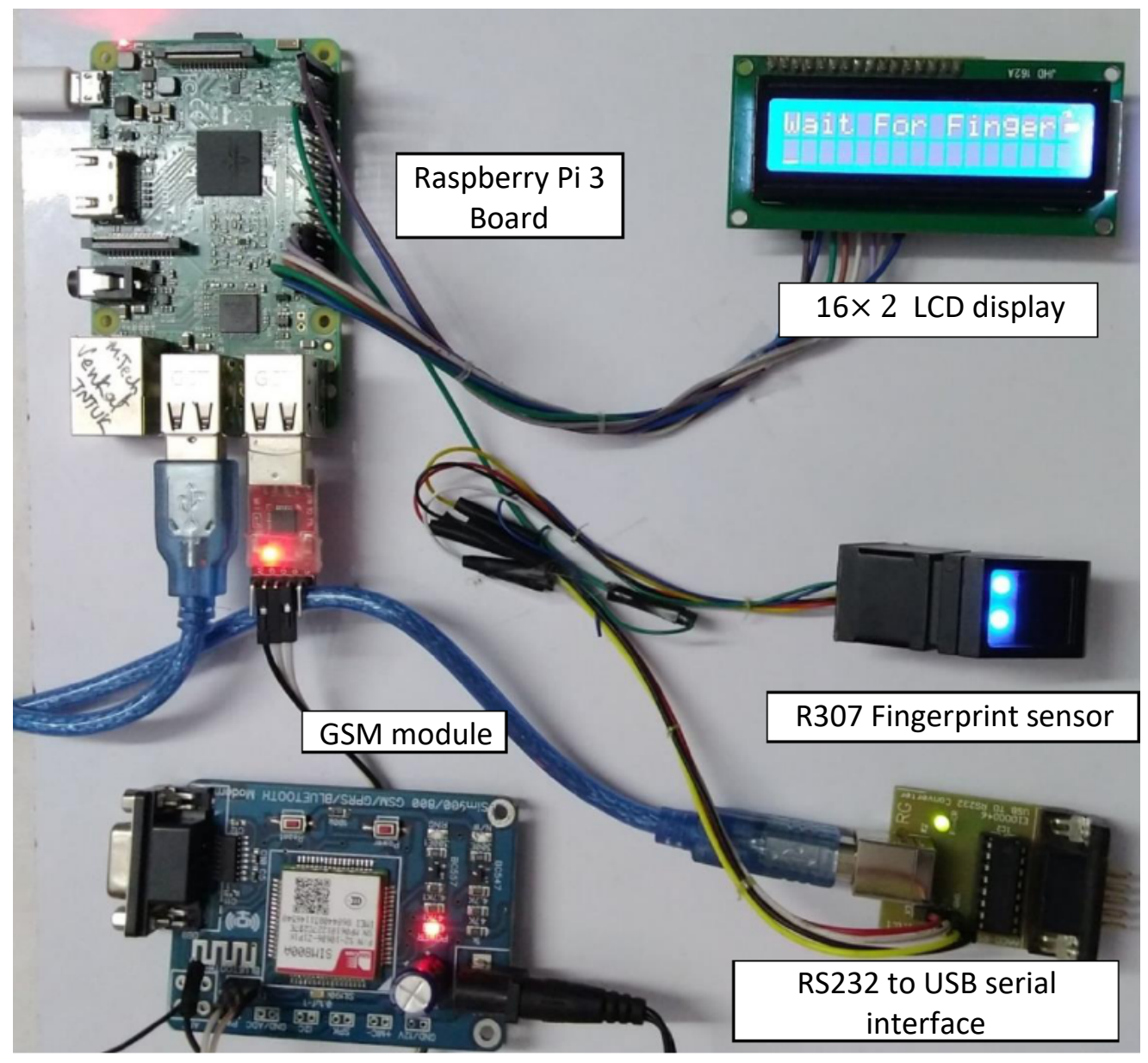

Figure 8 Experimental Setup of BARCS 9.

When we initialize the system, the LCD welcome message is displayed as shown in Figure

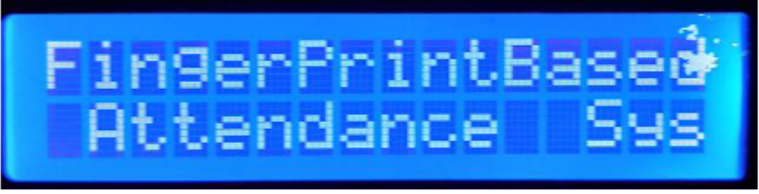

Figure 9 Welcome Message on LCD Display

After initializing the LCD, the GSM module is also initialized and LCD displays as "GSM Module OK" shown in Figure 10. 
Biometric Based Attendance Registration and Consolidation System Using Raspberry PI3 and Amazon Web Server

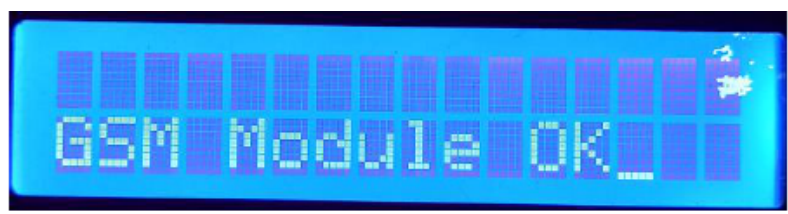

Figure 10 GSM module initialization message on LCD

When the fingerprint sensor is initialized the LCD displays "Wait for Finger" as shown in Figure 11 .

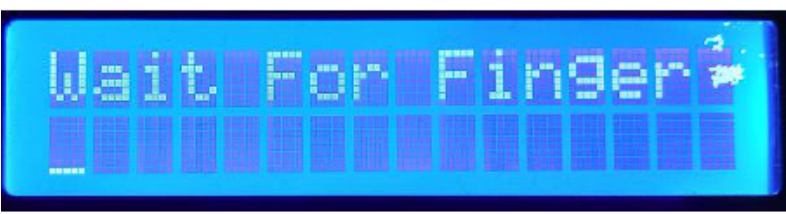

Figure 11 "Wait for Finger message" is displayed on LCD initially before start of the session

At the beginning of the class (session), when the faculty places his fingerprint, "Finger Found" message is displayed on LCD, if his fingerprint matches with the fingerprints in the faculty database stored in the fingerprint module (Figure 12). The Faculty ID and Name are displayed on the LCD as shown in Figure 13.

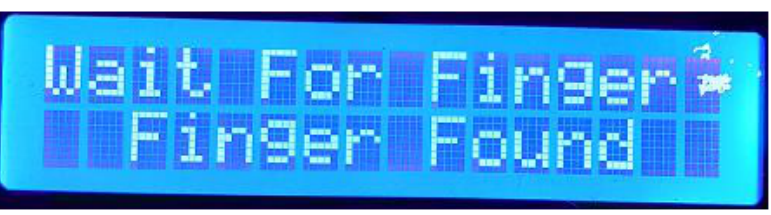

Figure 12 "Finger Found" message is displayed on LCD when Faculty fingerprint matches to start the session

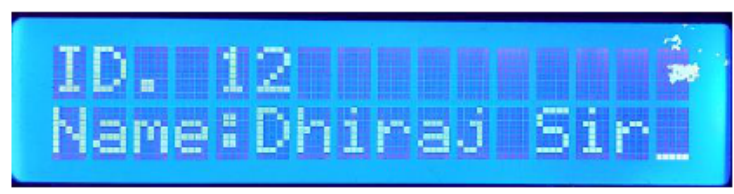

Figure 13 Faculty ID and Name are displayed on LCD when Faculty fingerprint matches at the start of the session

Similarly, when a student registers his attendance by placing his fingerprint on the Biometric Attendance Recording Device (BARD), attendance status will be shown on LCD and a SMS is sent to student's mobile as shown in Figure 14.

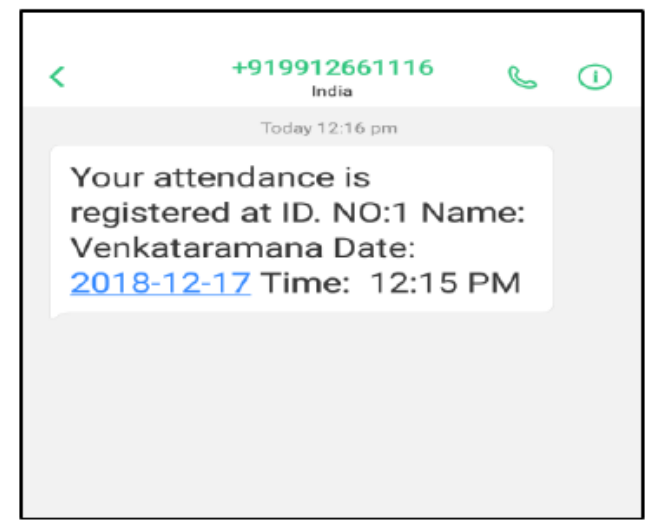

Figure 14 SMS is sent to student's mobile along with date and time stamp when his attendance gets registered 
By entering the IP address of the Raspberry Pi, user can login to the BARCS webpage. Figure 15 shows the snapshot of the developed webpage. On the web page, all the subjects names are displayed. By clicking on a particular subject, we can get the corresponding subject attendance. The attendance will be displayed as total classes, present classes, absent classes, and attendance percentage.

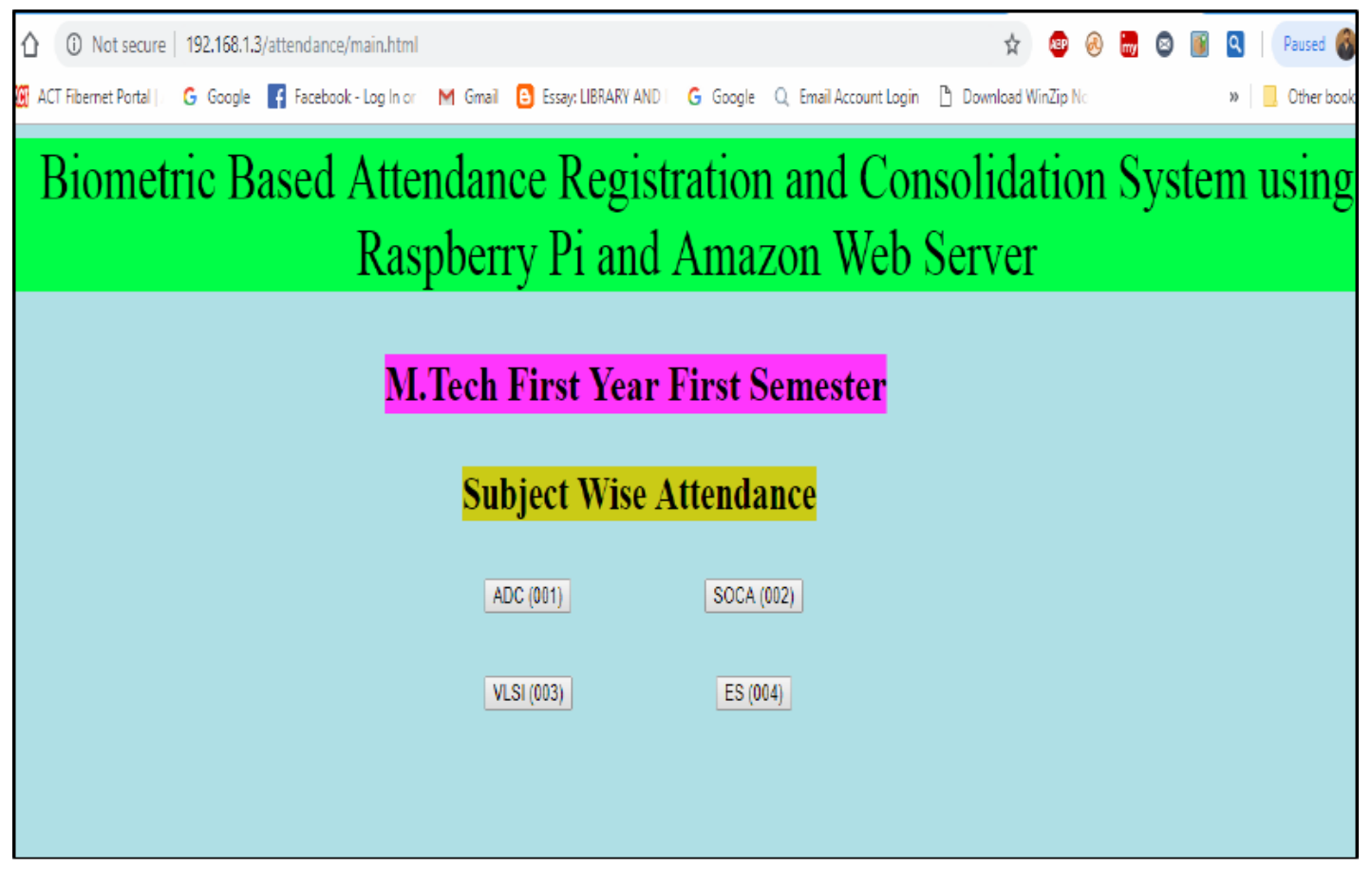

Figure 15 Snapshot of developed Webpage of BARCS

Sample consolidated student attendance particulars in the subject of System Advanced Data Communications (ADC) for M.Tech I Year I Semester are shown on the webpage (Figure 16). This data is stored in My SQL database. In this investigation, we have taken the total number of students in the class to be five.

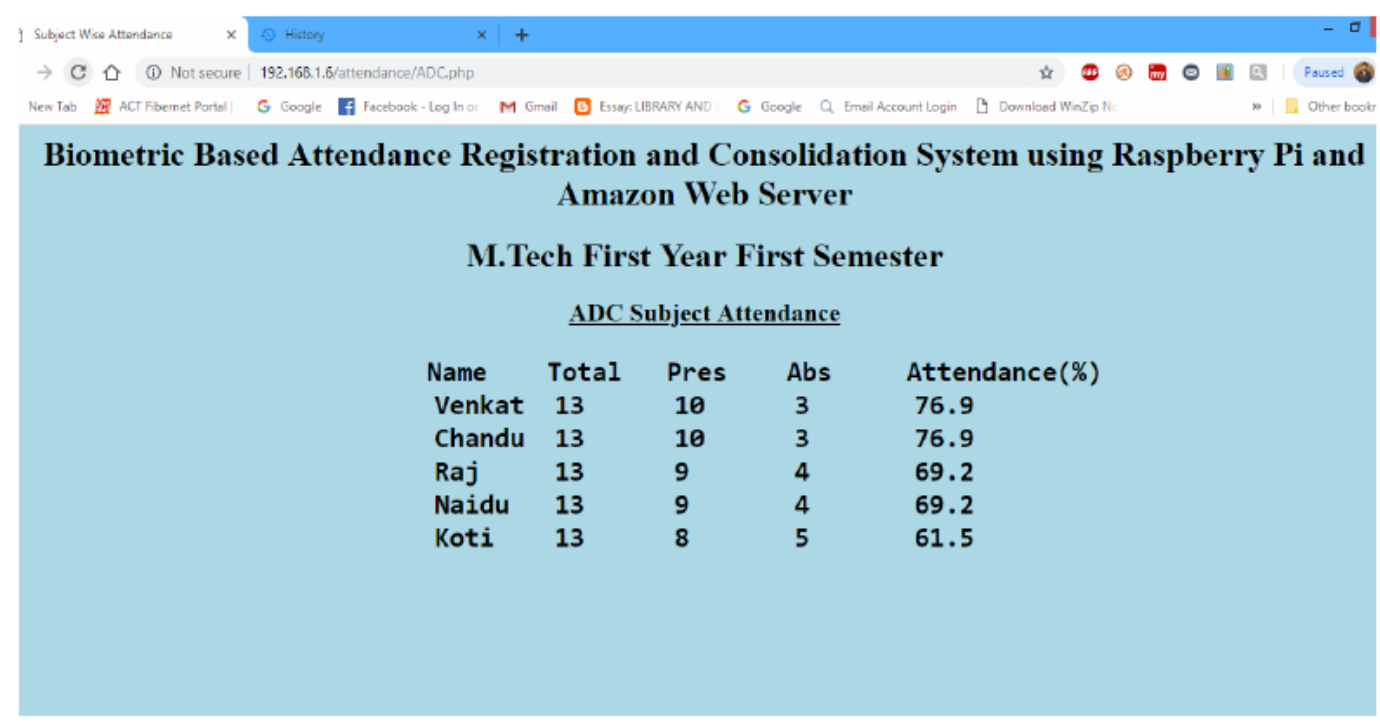

Figure 16 Snapshot of developed Webpage showing consolidated attendance of all students along with percentage of attendance 
Biometric Based Attendance Registration and Consolidation System Using Raspberry PI3 and Amazon Web Server

\section{CONCLUSIONS}

In the proposed attendance management system, a portable biometric based attendance recording and consolidation system is developed. This system saves a good amount of time of the teacher as the teacher need not callout student name and enters the attendance manually in a register. This system reduces the required manpower for feeding the attendance into a computer and avoids use of special software for required to calculate the attendance percentage. As it is a biometric system, it is more secure. The message alert feature helps the student to know that his attendance is registered.

\section{REFERENCES}

[1] Srinidhi MB and Romil Roy, A web enabled secured system for attendance monitoring and real time location tracking using Biometric and Radio Frequency Identification (RFID) technology, International Conference on Computer Communication and Informatics (ICCCI), 8-10 Jan. 2015, Coimbatore, India, pp. 1-5, IEEE.

[2] Amena Khatun, A.K.M. Fazlul Haque, Sabbir Ahmed, Md. Mahfujur Rahman, "Design and implementation of iris recognition based attendance management system", International Conference on Electrical Engineering and Information Communication Technology (ICEEICT), 21-23 May 2015, Dhaka, pp.1-6, IEEE.

[3] S.Poornima, N.Sripriya, B.Vijayalakshmi, P.Vishnupriya, "Attendance monitoring system using facial recognition with audio output and gender classification”, International Conference on Computer, Communication and Signal Processing (ICCCSP), 10-11 Jan. 2017, Chennai, India, pp. 1-5, IEEE.

[4] S. Sunil Jadhav, S. Akash Gagare, Pooja Gunjal, Jagtap Vidya, "Android Based Smart Attendance System using QR Code: A Review", International Journal of Advance Research and Innovative Ideas in Education, Vol.4, Issue 3, 2018, pp.1096-1099.

[5] Dhiraj Sunehra and V. Surender Goud, "Attendance Recording and Consolidation System using Arduino and Raspberry Pi”, International Conference on Signal Processing, Communication, Power and Embedded System (SCOPES), Paralakhemundi, India 3-5 Oct. 2016, pp.1240-1245, IEEE.

[6] https://www.raspberrypi.org/

[7] Rhydo Technologies (P) Ltd., "SIM900-RS232 GSM/GPRS Modem User Manual”, 2011.

[8] https://en.wikipedia.org/wiki/PuTTY.

[9] Richard L. Halterman, "Learning to Program with Python", 2011 (www.cs.uky.edu/).

[10] Larry Ullman, "PHP for the Web", Peachpit Press, San Francisco, 2016.

[11] Deepika Yadav, Yogendra Singh and Harshit Gupta, Controlling of Relay using Raspberry Pi Via Internet for Home Automation. International Journal of Advanced Research in Engineering and Technology, 9(1), 2018, pp 1-11.

[12] Dr.Raju Anitha, S.Harsha Vardhan, Ch.Akhil and G.Sona, An Automated SMS-Update System through IOT using Raspberry $\mathrm{Pi}$, International Journal of Mechanical Engineering and Technology 9(1), 2018, pp. 118-124.

[13] Bhagya Maybel $\mathbf{J}$ and A. Umamakeswari, Hardware Implementation of Secure Image Transmission in Raspberry PI, International Journal of Mechanical Engineering and Technology 9(2), 2018, pp. 670-678.

[14] Mohamed Basheer. K. P and Dr. T. Abdul Razak, Enhanced Biometric Based Authentication for Network Security Using Iris, International Journal of Computer Engineering and Technology (IJCET), Volume 4, Issue 6, November - December (2013), pp. 414-422

[15] R.M.Vithlani, Sagar Shingala and Dr. H.N.Pandya, Biometric Automobile Ignition Locking System, International Journal of Electronics and Communication Engineering and Technology, 7(5), 2016, pp. 28-37.

[16] B. Sateesh Kumar and Dr.A.Govardhan, Analysis of Bipartite Rankboost Approach for Score Level Fusion of Face And Palmprint Biometrics, International Journal of Computer Engineering and Technology (IJCET), Volume 6, Issue 4, April (2015), pp. 01-07 